\title{
La elite de la "vieja izquierda" en las batallas de la memoria: la conmemoración del 11 de septiembre en dictadura*
}

\section{The elite of the "old left" in the battles of memory: the commemoration of September 11 in dictatorship}

Renato Dinamarca Opazo ${ }^{* *}$

\begin{abstract}
Resumen
El presente artículo se pregunta cómo las elites del Partido Comunista y del Partido Socialista contribuyeron en la construcción de memorias emblemáticas mediante las conmemoraciones del 11 de septiembre en el periodo de dictadura militar. Proponemos que en las conmemoraciones las elites políticas resignificaron el pasado de acuerdo al presente en que se encontraron insertos y a sus horizontes de futuro. De esta manera, la resignificación del pasado estaría condicionada por las coyunturas políticas que se desarrollaron entre 1973 y 1988, y especialmente por las vías por las que los partidos se oponen y hacen visible la salida de la dictadura.

Palabras claves: Elites de izquierda- usos del pasado - Conmemoración - 11 de septiembre.
\end{abstract}

\begin{abstract}
This article asks how the elites of the Communist Party and the Socialist Party contributed to the construction of emblematic memories in the period of military dictatorship. We propose that in the commemorations political elites meant the past according to the present found that inserts and their future horizons. Thus, the redefinition of the past would be conditioned by the political situation that developed between 1973 and 1988, and especially the ways in which parties oppose and make visible the end of dictatorship.
\end{abstract}

Keywords: Elites leftist- uses of the past- commemoration- September 11

\footnotetext{
El texto presentado a continuación es parte de mi tesis de grado, guiada por la Dra. Cristina Moyano y se presentó en las VII Jornadas de Trabajo Sobre Historia Reciente, realizadas en La Plata, Argentina, durante el mes de agosto del año 2014, bajo el nombre "Memoria y conmemoración: El 11 de septiembre de la elite de izquierda en tiempos de dictadura". Si bien la base del texto es la misma, en el presente se agregan referencias y citas que se habían omitido para facilitar la exposición oral.

${ }^{\star \star}$ Chileno, Licenciado en Historia, mención Tiempo Presente por la Universidad Academia de Humanismo Cristiano. El presente texto se llevó a cabo gracias a los recursos proporcionados por proyecto FONDECYT N¹120009 titulado "Poder, prestigio y riqueza: Transformación de la elite regional en el "Gran Concepción". Del Estado desarrollista al Estado neoliberal 1957-1990", dirigido por la Dra. Cristina Moyano Barahona, en el cual participé como tesista. Por otra parte, se financió con los recursos proporcionados por el Concurso de Tesis del Museo de la Memoria y los Derechos Humanos del año 2013. Contacto: re_dinamarca@hotmail.com
} 


\section{Introducción}

El presente trabajo aborda la construcción de memorias emblemáticas por parte de las elites políticas de izquierda durante el periodo de la dictadura militar chilena (1974-1988) en las conmemoraciones del 11 de septiembre. Este trabajo, relacionado con las prácticas culturales de la elite política de la izquierda, pretende llenar un vacío en el estudio de los aspectos subjetivos de dichos actores al presentarlos como constructores de memoria.

En general, las conmemoraciones del 11 de septiembre han sido una problemática poco investigada en Chile, a pesar de que las investigaciones al respecto sean sobresalientes. Por una parte, destaca el trabajo de Azun Candina (2002: pp. 9-48), quien desde la historia social historiza las batallas de la memoria en torno al golpe militar. Este trabajo es pionero y demuestra un profundo trabajo de fuentes orales y periodísticas, pero deja de lado una cantidad importante de fuentes de los partidos de izquierda en torno a las conmemoraciones del 11 de septiembre, utilizando además una cantidad importante de prensa oficial, El Mercurio por ejemplo, como fuente histórica, lo cual es válido siendo conscientes de la visión sesgada que dicho periódico de derecha utiliza. En este sentido, creemos que existen actores políticos relevantes en la construcción de memoria que fueron invisibilizados en su trabajo. Desde la ciencia política, conocemos el trabajo de Alfredo Joignant (2007), quien realiza, en una perspectiva general, un trabajo en torno a la conmemoración del Estado y su evolución desde 1974 al siglo XXI, destacando en su perspectiva la batalla que se dio a nivel estatal entre la figura de Augusto Pinochet y Salvador Allende, lo cual representa la pugna entre dictadura y democracia. Si bien este trabajo también concita interés por la capacidad crítica de su autor, también deja de lado actores políticos que se convirtieron en importantes portavoces de memoria.

Por otra parte, investigar la relación problemática de la memoria y la conmemoración del 11 de septiembre resulta pertinente cuando a un año del cumplimiento de los cuarenta años del golpe militar, el espíritu conmemorativo inundó la opinión pública, estado ausente la reflexión sobre el devenir de estas prácticas. En este sentido nos preguntamos ¿Cómo las elites políticas del Partido Comunista (PCCH) y el Partido Socialista (PS) contribuyeron a formar memorias emblemáticas durante la dictadura militar (1974-1988)? Las conmemoraciones son momentos en que las memorias emblemáticas emergen expresando su conflictividad en el espacio público, lo que nos permite apreciar las disputas sociales por el pasado de diversos actores políticos. Nuestra hipótesis de trabajo es que durante la dictadura militar en Chile (1973-1988) las elites de la izquierda chilena, en particular del PS y del PCCH, actuaron como importantes portavoces de la resignificación del pasado a través de la construcción de memorias emblemáticas durante las conmemoraciones del 11 de septiembre. Estas conmemoraciones no fueron idénticas durante el periodo, sino que estas son prácticas en que las elites políticas resignificaron el pasado de acuerdo al presente en que se encontraron insertos y a sus horizontes de futuro. De esta manera, la resignificación del pasado estaría condicionada por las coyunturas políticas que se desarrollaron entre 1973 y 1988, y especialmente por las vías por las que los partidos se oponen y hacen visible la salida de la dictadura. 


\section{Elite política, memoria emblemática y conmemoración}

Nuestra definición de elite política se asocia principalmente a una perspectiva institucional, es decir, planteamos que la elite política era aquella que ocupaba cargos de dirección, definición que "presenta la ventaja de proporcionar un punto neto de separación entre pertenencia y no pertenencia" (Nagle, John; 1979: p.22). Partiendo de esa base, también nos acercamos a los liderazgos políticos no institucionales, pero que comparten experiencias generacionales con miembros de las direcciones. Tatiana Herrera dirá que "cada partido político posee un cuerpo legal estatuido, el que provee la organización y el funcionamiento interno, los estatutos internos reflejan la costumbre y cultura política que con el tiempo se fue rutinizando al punto de ser racionalizada legalmente. Este cuerpo legal y racionalizado provee el gobierno de la ley y el sistema de generación de liderazgos políticos, específicamente el liderazgo político formal" (2005: p. 95).

Por otra parte, en los partidos de izquierda también hubo nuevas generaciones de militantes que sin ser parte de la dirección, poseían gran influencia, ya sea por su labor intelectual, pública, etc. En este sentido, también pusimos atención a liderazgos políticos no institucionales relevantes para nuestra investigación, es de decir, que por algún motivo su actividad pública o elaboración intelectual influyó en las formas de conmemorar el 11 de septiembre. Siguiendo a Herrera nominaremos este tipo de liderazgo como "informal", el cual se acerca a una autoridad carismática "cuyo poder se encuentra basado en el poder carismático que le provee la existencia y el reconocimiento de sus pares de ciertas características fuera de lo común, lo que puede acercarse al fenómeno del caudillismo en algunos casos, dependiendo del grado de institucionalidad política partidista que exista al interior del sistema de partidos estudiado" (2005: p. 96).

De esta manera, planteamos que para el periodo investigado, durante el cual la política pública fue clausurada, la elite y los líderes políticos de la izquierda, es decir, quienes "constituyen el sector más visible, el que ejerce más influencia en las formas identitarias que toman los partidos en la vida política de un país" (Moyano, Cristina; 2008) buscaron llevar a cabo la "lucha política por la significación de la realidad" (Moyano, Cristina; 2009: pp. 55-86), convirtiéndose en lo que Steve Stern denomina "portavoces de la memoria", quienes llevaron a cabo "el proceso de deseo y de lucha para construir las memorias emblemáticas, culturalmente y políticamente influyentes y hasta hegemónicas" (2000: p. 13).

Para los efectos de la investigación nos referiremos a la memoria en su dimensión colectiva, concepto introducido por el sociólogo Maurice Halbwachs. Según Elizabeth Jelin, un elemento importante que plantea el enfoque de Halbwachs, es la noción de marcos o cuadro social de memoria. En este sentido, "las memorias individuales están siempre enmarcadas socialmente. Estos marcos son portadores de la representación general de la sociedad, de sus necesidades y valores. Incluyen también la visión de mundo animada por valores, de una sociedad o grupo" (1998: p. 20). Así, según el postulado de Halbwachs, sólo es posible recordar "cuando es posible recuperar la posición de los acontecimientos pasados en los marcos de la memoria colectiva" (1998: p. 20). 
Renato Dinamarca, La elite de la "vieja izquierda" en las batallas de la memoria: la conmemoración del 11 de septiembre en dictadura / The elite of the "old left" in the battles of memory: the commemoration of September 11 in dictatorship, Revista Izquierdas.cl, número 22, enero 2015, ISSN 0718-5049, Santiago de Chile, pp.180-203

Este elemento en torno a la memoria colectiva es rescatado por Stern para agrupar las diferentes memorias sueltas o individuales en marcos denominados "memorias emblemáticas". Para Stern las memorias emblemáticas son "una especie de marco, una forma de organizar las memorias concretas y sus sentidos, y hasta organizar los debates entre la memoria emblemática y su contra memoria" (2000: p. 14). Esta "da sentido interpretativo y un criterio de selección a las memorias personales, vividas y medio sueltas, pero no es una sola memoria, homogénea o sustantiva. Los contenidos específicos y los matices no son idénticos ni de una persona a otra, ni de un momento histórico a otro" (2000: 14). La memoria suelta o individual se convierte en memoria emblemática, cuando esta se relaciona con el proceso histórico nacional (2013). De esta manera, no existiría sólo un marco de la memoria emblemática, sino que convivirían por lo menos cuatro en la sociedad chilena, asociados a diferentes formas de vivir y recordar el golpe militar de 1973. La primera es la "memoria como salvación", que plantea que el golpe militar liberó al país del caos que el gobierno marxista había provocado. En segundo lugar, está la "memoria como ruptura lacerante no resuelta" que se relaciona con aquellas personas que vivieron la desaparición de familiares o el drástico cambio de sus vidas, sufriendo una ruptura no resuelta tras el golpe militar, lo que da origen a una doble personalidad en esas personas, ya que viven su vida cotidiana con normalidad, pero en su interior viven con un duelo imposible de cerrar. En tercer lugar, está la "memoria como prueba de una consecuencia ética y democrática", la cual se liga a aquellas personas que no sufren la desaparición directamente, pero luchan en contra de las violaciones de los derechos humanos y la dictadura por un compromiso personal. Por último Stern plantea la existencia de una "memoria como olvido o como caja cerrada". Según esta memoria, el golpe militar y la dictadura son temas explosivos que conviene evitar para no provocar conflictos y favorecer la reconciliación y reencuentro nacional. En la metodología propuesta por Stern para el estudio de la Historia de la memoria, existen nudos convocantes de la memoria y el olvido, es decir, actores humanos, hechos, fechas y lugares que exigen "construir sus puentes de memoria y así encontrar su verdad" (2000: p. 14). Las conmemoraciones del 11 de septiembre serían uno de estos nudos.

En términos del historiador John Gillis, nosotros estudiamos la fase de la conmemoración "post nacional" (1996), en la cual "comienzan a pujar por manifestarse las memorias de grupos subalternos, que cuestionan y contradicen la memoria oficial" (Jelin, Elizabeth; 2002: p. 4), memorias que "pueden ser las anclas para elaborar prácticas de resistencia y construir poder opositor a la versión dominante" (Jelin, Elizabeth; 2002: p. 4). En síntesis, en el presente trabajo abordaremos la dimensión en que la conmemoración se plantea como un "uso del pasado". Esta categoría "alude a la utilización que del pasado hacen grupos e instituciones de una sociedad por cuestiones identitarias y/o de intereses ligados al presente" (Montaño, Eugenia; 2010: p. 16), es decir, alude a las luchas memoriales llevada a cabo por ciertos grupos en la sociedad, los cuales buscan que su representación de la sociedad se transforme en hegemónica. De esta manera desplazamos la atención hacia las "condiciones de producción político cultural de cada presente" (Rabotnikof, Nora; 2009: p. 189) y en especial a "las agregaciones generacionales, los intereses hegemónicos" (Rabotnikof, Nora; 2009: p. 189) de los grupos a investigar. 
Nuestra metodología de investigación contempló la revisión histórica de fuentes, aplicada a la prensa partidaria ${ }^{1}$, novelas ${ }^{2}$ y biografías de militantes ${ }^{3}$, así como a bibliografía histórica ${ }^{4}$. En cuanto a la prensa, pensamos es un reflejo de la elaboración teórica y política de la elite política de cada partido. Por otra parte, utilizamos complementariamente la metodología de la historia oral, buscando conocer las experiencias militantes en las conmemoraciones ${ }^{5}$. El siguiente texto se organizó a modo de síntesis analítica mediante tres apartados, el primero que trata sobre la década de los setenta, un segundo que trata de la década de los ochenta y un tercero que consiste en una breve conclusión en la que presentamos algunas preguntas no resueltas que dejó nuestra investigación ${ }^{6}$.

\section{Conmemorando en la década de los setenta}

En el periodo 1973-1979 los dirigentes de la izquierda, tanto en Chile como en el exilio, comenzaron a forjar puentes entre su realidad y la de todos los chilenos. Esta realidad, en el periodo 1973-1976, se caracterizó por las más brutales violaciones a los derechos humanos de la dictadura chilena. $\mathrm{Al}$ interior del $\mathrm{PCCH}$, la década estuvo marcada por la discusión de mantener o modificar la política del Frente Antifascista como forma de hacer oposición a la dictadura, el cual era una suerte de continuación de la línea política de Frente Popular adoptada por el PCCH en la década de los treinta por la "Generación del 38", integrada entre otros por Luis Corvalán, Orlando Millas, Volodia Teitelboim, Américo Zorrilla, Mario Navarro, Jorge Montes, Rodrigo Rojas, Inés Cornejo, Víctor Cantero, Hugo Fazio y Luis Guastavino, Víctor Díaz, Mario Zamorano, Jorge Muñoz, Fernando Ortiz, Waldo Pizarro, Horacio Zepeda y Fernando Navarro, parte de los cuales hoy en día son detenidos desaparecidos. Dicha generación nació bajo la lucha contra el nazi-fascismo, en el contexto previo a la Segunda Guerra Mundial, y se mantuvo en la dirección, casi sin cuestionamientos, hasta fines de la década de los setenta.

Mientras dicha línea política estuvo vigente, el pasado y el campo de experiencia extendieron la visión de la historia de Chile del PCCH hasta periodos de fundación de la Republica. De esta manera, con la nostalgia del exilio, en las conmemoraciones del 11 de septiembre el golpe militar era resignificado como un punto negro dentro de la historia nacional, de la cual se rescataban los elementos libertarios del poder extranjero representados por Bernardo O'Higgins en relación con la corona española en el contexto de la Independencia, la rebeldía popular encarnada en Manuel Rodríguez, el proyecto

\footnotetext{
${ }^{1}$ Entre la prensa partidaria que utilizamos para investigar al PCCH están el Boletín Exterior, el Boletín de prensa El Siglo, la revista Basta y la revista Principios. Para el PS utilizamos el periódico Unidad y Lucha, el Boletín Juventud Socialista de Chile, el Boletín Informativo del Bloque Socialista y el Boletín del Comité Central, entre otros.

${ }^{2}$ Las novelas que utilizamos en nuestra investigación son las siguientes: (Saldias, Claudio; 1998; Saldias, Claudio; 2007; Palma, Ricardo; 2001; Carrera, José; 2013).

${ }^{3}$ Ver (Fernández, Joaquín et al; 2013; Corvalán Lepe, Luis, 1997).

${ }^{4}$ Respecto al PCCH ver (Álvarez, Rolando; 2003 y 2011; Bravo, Viviana; 2010). Respecto al PS ver (Drake, Paul; 1992; Gutiérrez, Eduardo, 2003; Ortiz, Edison; 2007; Yocelevzky, Ricardo; 2002)

${ }^{5}$ Entre aquellos militantes de izquierda que entrevistamos están Patricio Quiroga, Ricardo Brodsky, Manuel Fernando Contreras y Patricio Hales.

${ }^{6}$ Para profundizar en las conmemoraciones del PCCH en dictadura ver (Dinamarca, Renato; 2013).
} 
industrializador de los Presidentes José Manuel Balmaceda y Pedro Aguirre Cerda, así como la obra revolucionaria del gobierno de la Unidad Popular (UP), con el Presidente Salvador Allende a la cabeza. En 1976 el PCCH plantea en su Boletín Exterior que:

Hay una línea de continuidad desde O’Higgins a Salvador Allende en las luchas progresistas de Chile a favor de la libertad y la democracia. Nuestro país alcanzó gran prestigio en América y en todo el mundo precisamente por sus tradiciones y su vida democrática pero, el golpe de estado del 11 de septiembre los ahogó en sangre. De ahí el repudio a la junta fascista y la gran solidaridad con nuestro pueblo. El amor a la libertad y a la democracia está en el corazón y en la conciencia de los habitantes de nuestra tierra y no han renunciado jamás a estos valores (Boletín Exterior; 1976: p. 5).

Para el PCCH será el pasado y su relectura la forma primordial de dotar de sentido la acción política presente. Por otra parte, el centro de la disputa por el pasado también le permitió al PCCH situarse dentro del campo de la crítica hacia el resto de la izquierda sobre los errores del gobierno de la UP, manteniendo su posición firme respecto de la unidad de la izquierda, el respeto a la democracia y a las alianzas pluriclasistas, dejando en claro que fueron otros los responsables de la derrota, precisamente por no propender a la unidad, tal como era el caso del Movimiento de Izquierda Revolucionaria (MIR). De esta manera, el PCCH evitaba la autocrítica asumiendo sus propios errores en la derrota.

En Chile, luego de la represión más dura, que se prolongó hasta el año 1976, las verdades que la dictadura quería mantener ocultas fueron sacadas a la luz pública, principalmente por los familiares de los detenidos desaparecidos, quienes se convirtieron en referentes simbólicos para parte de los chilenos y para aquellos que en el extranjero solidarizaban con en la lucha anti dictatorial. Progresivamente, estas verdades empalmaron con los imaginarios y representaciones que significaban al golpe y la dictadura como la antítesis de la esencia de la patria y del ser chileno. En las conmemoraciones, la elite del PCCH fue enfática en la propagación de la experiencia histórica vivida desde el golpe, lo cual contribuía a la construcción de un movimiento de masas de oposición a la dictadura y la conformación de una unidad política con el conjunto de los partidos que estaban legalmente impedidos de funcionar. Sin embargo, para una cantidad importante de líderes políticos más jóvenes que los miembros de la Dirección Exterior, formados al calor de los acontecimientos de la década de los sesenta inaugurada por la Revolución Cubana, la línea política de Frente Antifascista había llegado a su agotamiento a mediados de los setenta, por lo que comenzaban a tener la certeza de que a la dictadura había que derrocarla, que no se iría por su propia voluntad (Álvarez, Rolando; 2003). En este sentido, la violencia comenzó a ser vista como una herramienta más en la lucha anti dictatorial. Este proceso se desarrolló casi paralelamente a la constitución de una Equipo de Dirección Interior (EDI), que mas tarde se transformó en la Dirección del PCCH, y que estuvo integrada mayoritariamente por sectores de esta generación.

Entre los integrantes de esta generación destacan en el exilio Gladys Marín, Manuel Fernando Contreras, Augusto Samaniego, Carlos Zúñiga y Patricio Palma, quienes fueron 
influenciados no sólo por la Revolución Cubana de 1959, sino que también por la denominada Reforma Universitaria de 1968 y por las Guerras de Liberación Nacional del Tercer Mundo, lo que constituyó en ellos una percepción distinta de la actividad revolucionaria de la que tenían los líderes de la denominada "Generación del 38". Por otra parte, el triunfo de los revolucionarios nicaragüenses en 1979 fue un impulso para parte de esta generación que, luego de un nuevo triunfo revolucionario por medio de las armas en la región, comenzó a plantear decididamente la necesidad de llevar a cabo una confrontación armada en contra de la dictadura.

Se abría así un momento único en la historia comunista de Chile, en donde el problema militar era un elemento central en la reflexión política, momento que tendría su máximo desarrollo en la década de los ochenta. A la vez, este giro en la visión de la realidad tuvo como consecuencia que durante las conmemoraciones del periodo 1977-1979, el PCCH pusiera su atención en la construcción de expectativas hacia el futuro, lo cual, tal como lo ha planteado Álvarez (2003), tuvo su correlato en la selección de las tradiciones recuperadas desde el pasado, lo que se manifiesta en el interés por figuras tradicionales de la experiencia militar de la independencia chilena. En 1979 el periódico Basta de las Juventudes Comunistas expresaba lo siguiente:

La imagen del patriota rebelde, contra el poder colonial y aristocrático está en nuestra sangre, palpita en nuestro quehacer diario, por cumplir, un precepto O'Higginiano; expulsar al poder extranjero enquistado en la economía y la sociedad, recuperando para Chile y los chilenos su propia tierra. Es ser patriota luchar contra la tiranía, es ser patriota conquistar la conciencia de las mayorías para construir un Chile justo, digno y democrático, un Chile como el que quería Bernardo O’Higgins Riquelme, nuestro libertador. (Basta; 1979).

El saldo de la primera década de dictadura fue la constitución de un mundo de sentidos que posibilitó que en la próxima década los militantes comunistas se sintieran imbuidos en una mística y subjetividad que rememoraba tanto las luchas por la libertad vividas por los próceres de la independencia, de las que era rescatada la voluntad de liberación del yugo extranjero y el espíritu revolucionario de los denominados padres de la patria, como las luchas de los explotados llevadas a cabo durante el siglo XX, encarnadas en Luis Emilio Recabarren, Pedro Aguirre Cerda y Salvador Allende. Por otra parte, la introducción de la violencia como herramienta para hacer frente a la dictadura, también se relacionaba con la recuperación de la dignidad perdidas tanto por la vergüenza de no haber sabido defender al gobierno popular, como por no haber sido capaces de responder los golpes represivos de la Dirección de Inteligencia Nacional (DINA) (Álvarez, Rolando; 2003; Bravo Viviana; 2010). Será esta totalidad de sentidos la que permitirá que los militantes comunistas estuvieran dispuestos a dar su vida en la lucha en contra de la dictadura. En este sentido, tanto la memoria de una consecuencia ética y democrática, dominante en el exterior del país, como la memoria emblemática de ruptura lacerante, difundida sobre todo luego de 1976, permitían sentir que la lucha contra la dictadura era una contribución a la gesta libertaria del pueblo chileno, gesta que se remontaba al 
nacimiento de la nación libre. Sin embargo, producto de la introducción de estos nuevos elementos a la cultura política comunista, la experiencia de lucha contra la dictadura en la década de los ochenta comenzó a dejar atrás el anclaje en el pasado remoto que validaba su línea política de oposición a la dictadura, para comenzar a centrarse en el presente y las expectativas del futuro.

Por su parte, desde el mismo momento en que se produce el golpe, el PS vivió una crisis interna. Su cultura política fraccionalista (Drake, Paul, 1992) hizo que se produjera una explosión orgánica, por lo que nacieron múltiples grupos que luchaban por la legitimidad y la herencia del partido de Allende. Esto tuvo como consecuencia que el debate ideológico y la elaboración teórica fuera de suma importancia dentro de los líderes socialistas (Yocelevsky, Ricardo; 2002). Por otra parte, a nivel interno, el PS también era un partido más proclive a los recambios generacionales, por lo que a diferencia de lo que sucedió con el PCCH, en donde la "Generación del 38" se mantuvo en los cargos directivos hasta finales de la década de los setenta, en el PS las generaciones impregnadas por el espíritu de los sesenta se habían hecho del poder del partido en el Congreso de Chillan de 1967. De esta manera, el PS fue un partido mucho más permeable a la influencia de la ultra izquierda. En este sentido, luego del golpe, la hegemonía del partido, por lo menos en el Chile, estuvo en manos de la "Generación Elena", formada por miembros de las guerrillas guevaristas derrotadas en Bolivia, así como por jóvenes socialistas que se declaraban como "hijos del Che". Los miembros de la Comisión Política que asume la dirección del PS luego del golpe fueron Exequiel Ponce, quien era miembro del Comité Central electo en el Congreso de La Serena, Carlos Lorca, Diputado y Secretario General de las Juventudes Socialistas (JJSS), Ricardo Lagos Salinas, Gustavo Ruz, Víctor Zerega y Ariel Mancilla, de los cuales sólo Ruz es un sobreviviente (Gutiérrez, Eduardo; 2003: p. 56). Dicha generación planteaba la necesidad de dejar atrás la tradición asambleísta y parlamentaria del PS para adoptar definitivamente un funcionamiento orgánico leninista (Ortiz, Edison; 2007).

En un primer periodo, 1974-1976, las discusiones del PS no anclaron su rememoración del pasado en los orígenes de la nación, tal como lo hiciera el PCCH. Su carácter nacional, autóctono, y el hecho de que Allende fuera militante del PS, hicieron que la reflexión estuviera mucho más marcada por lo que se consideró errores del periodo 19701973 y de las propuestas para su solución, las cuales no diferían sustancialmente de las posiciones que las fracciones tenían previo al golpe militar. El militante socialista Patricio Quiroga, quien fuera miembro del Grupo de Amigos del Presidente (GAP), formado para el resguardo de la seguridad personal de Salvador Allende y que en 1974 se desempeño como enlace de la Dirección Interior, nos relató su experiencia en Chile:

La imagen del septiembre de 73' hasta el 74', está relacionada no con el 11 de septiembre, sino con el análisis de lo que había sucedido. El análisis y de las rearticulaciones en lo que posteriormente se conoció como Documento de Marzo, que fue el primer documento de la dirección clandestina. Documento del cual yo compartí en parte, otra parte no la compartí. ¿Cuál fue mi actividad allí? trasladarlo de un lugar a otro, como nexo de los miembros de la dirección. Ese documento no se plantea nada 
para septiembre, sino que el problema era como visualizar el carácter de la derrota y visualizar una línea estratégica para el futuro. (2013).

En general, en el exilio chileno los llamados a la solidaridad por las violaciones a los derechos humanos adquirían una fuerza notable. Dentro del PS las conmemoraciones del 11 de septiembre además tienen como rasgo notable que en el centro está puesto en el dolor y el impacto producido por el golpe y la dictadura militar, lo que incluía ciertos cuestionamientos de las actitudes de la dirección socialista durante el periodo anterior, los que se extendían inclusive al proyecto de Vía Chilena al Socialismo. Por otra parte, está presente el llamado al desarrollo de la Resistencia antidictatorial, la cual es entendida como la alternativa para dar salida a la dictadura, que en estos momentos se pensaba sería de corta duración. Respecto del dolor y el impacto en el PS citamos el siguiente párrafo:

Nuestro partido -como se reconoce- ha sido la colectividad política más dramáticamente golpeada y perseguida por la tiranía. No existe un solo hogar de socialista que no tuviera que lamentar la muerte, la prisión o el exilio de un camarada. El odio visceral de la dictadura hacia nuestro Partido es un odio monolítico, un odio de clase. Por ello quisiera vernos atomizados, destruidos, pulverizados para siempre, desmantelada la unidad revolucionaria del pueblo y sus vanguardias, y de estas entre sí. (Informativo $\mathrm{N}^{\circ} 22 ; 1976$ ).

En un segundo periodo conmemorativo, 1977-1982, es notorio un nuevo el énfasis en la construcción de la memoria heroica y combativa de Salvador Allende, cuya figura fue utilizada como un ejemplo a seguir por la Resistencia. Su muerte en combate y consecuencia democrática no es cuestionada por ninguna fracción del partido. También es notorio el tránsito de la construcción de una identidad socialista que va desde el trauma experimentado por el golpe, la cual se llevó a cabo en los momentos en que se llevaban a cabo las tareas de sobrevivencia personal y de reconstrucción del partido, luego de la caída de las direcciones en el periodo anterior (1975), a una memoria de la Resistencia y de lucha en contra de la dictadura, la cual también ponía el énfasis en la constitución de expectativas a las nuevas generaciones. De esta manera, ya no era el sufrimiento por la derrota lo que estaba al centro, sino que la intención de impulsar las luchas obreras y populares, la crítica al presente dictatorial y la construcción de un proyecto que, a futuro, ligara democracia y socialismo. Esta tarea fue obra de una generación continuadora de la obra llevada a cabo por la "Generación Elena", la "Patrulla Juvenil" (Gutiérrez, Eduardo; 2003), conformada por Iván Parvex, Carlos González, Eduardo Reyes, Benito Rodríguez y Oscar de la Fuente, a los que se les integraron más tarde Ricardo Solari, Eduardo Gutiérrez, Patricio Barra, Akin Soto, Albino Barra, Augusto Jiménez, Germán Correa, Luis Espinoza, María Lenina del Canto y Julio Stuardo. Esta dirección se constituyó por la cooptación vertical que llevaron a cabo los miembros de la "Generación Elena" antes que fueran hechos desaparecer por la DINA. La voluntad de crear una memoria de resistencia se expresa en la 
siguiente cita:

Cuando las próximas generaciones recuerden y hagan análisis de los años presentes, no será este periodo evocado, fundamentalmente, como uno de dictadura, sino como una época de lucha. Aunque vivamos hoy, y hace exactamente cinco años, la más cruel y eficaz dictadura que haya ahogado la patria, nuestros hijos pondrán el acento en la contraparte que esta crea: la organización popular bajo condiciones de aguda represión, las nuevas formas de lucha, el profundo replanteo histórico del proyecto de liberación nacional y la conciencia de la unidad como condición básica, no sólo para derrocar a la dictadura, sino como el único camino posible hacia una patria socialista. (Unidad y Lucha $\mathrm{N}^{\circ} 32 ; 1978$ ).

Por otra parte, en esta década, y sobre todo en el exilio, las conmemoraciones del 11 de septiembre fueron fechas de profundos análisis y debates en el socialismo chileno. Patricio Quiroga lo relató así:

Yo pasé algunos de esos aniversarios fuera de la RDA. En uno estuve en París, me acuerdo, y ahí había un debate muy fuerte respecto si esto había sido una derrota o un fracaso. Había incipientes discusiones. El hecho de que la Central Única de Trabajadores (CUT) se había transformado en una correa de transmisión del partido político, todavía no se hablaba de movimientos sociales. El 75' apareció muy fuertemente el tema de las mujeres, de lo femenino, también se discutía por allá. Las tesis de Althusser, de Poulantzas y especialmente me acuerdo algo que me sorprendió mucho, el descubrimiento que se hizo de Gramsci. Entonces aquella vez vi un debate, debe haber sido el 75-76, con estos tópicos, estos tópicos no estaban dentro del campo socialista, el debate del campo socialista era de una línea política más gruesa, no tenía el ribete teórico de Francia, era más bien un debate sobre estrategia y táctica. Y en otros países, en La Habana, los debates tenían mucho que ver con buscar una respuesta frente a la acusación de muchos cubanos de no haber muerto en la lucha. Habían críticas un poco exageradas, de los mismos cubanos que no entendían lo que había sido la vía político institucional, distinta a la vía armada. Entonces, dependía del lugar en que tú estabas, el tiempo de discusión. Ahora toda estaba centrada y concentrada también en una profusa discusión que salía del Chile Antifascista o de la Casa Chile. (2013).

Por otra parte, existen publicaciones que en el exilio comenzaron a cuestionar el giro leninista del partido. En este sentido, las conmemoraciones pasaban a ser un momento de debate público en donde se dejaba de lado la aceptación religiosa de la postura de la dirección radicada en Chile. Según las fuentes documentales disponibles en la actualidad, el ejemplo más notable de esto fue la conmemoración de 1978, la que fue utilizada como un 
momento estratégico por el Regional Europa, al parecer liderado por Erick Schnake ${ }^{7}$, para poner en cuestionamiento la concepción de la política y de partido político de la Dirección Interior, al tiempo que comenzaban la propuesta de un radical proceso de renovación teórica y metodológica. Sobre la evaluación del periodo 1970-1973 señalaban:

\begin{abstract}
No éramos nosotros los que quemábamos Chile de Arica a Punta Arenas: eran ellos quienes nos masacraban y encarcelaban de un extremo a otro del país...la noche cayó sobre nosotros. La Historia, cual testigo indiferente, nos sepultó y relegó, nos tortura aún y nos aventó por los confines mas confines del globo. En suma estuvimos presentes junto a la dialéctica de la derrota. Hoy vivimos las consecuencias de una derrota de la retórica disfrazada de dialéctica. (PS- Regional Europa; 1978: p.5).
\end{abstract}

Para el Regional Europa, “el 11 de septiembre marcó, a nuestro juicio, no sólo la fecha de una derrota gigantesca de los trabajadores chilenos, sino, además, la de la derrota de un tipo de enfoque y de una cierta forma de concebir la práctica política. Constituye, en definitiva, el fin de una cultura política de izquierda" (PS-Regional Europa; 1978: p.9). Esta cultura política estaría exenta de criterios de análisis, de planificación y evaluación, entre otros, lo que habría dado como resultado la centralización, el verticalismo y el autoritarismo, los que se habrían hecho norma luego del golpe debido al apoyo prestado al PS por parte de los países socialistas. Este proceso de crítica terminará con la más profunda separación del socialismo en el periodo, la que fue uno de sus rasgos principales durante la próxima década, y que generó dos visiones totalmente contrapuestas del pasado.

El saldo socialista de esta década es un tanto difuso, debido a que luego del golpe se producen múltiples rupturas, las cuales generan reflexiones y análisis en diferentes sentidos. Sin embargo, es patente que a través de las conmemoraciones del 11 de septiembre se constituyó una memoria y una identidad que relacionaba por una parte, a Allende y su heroica muerte con la necesidad de desarrollar una lucha anti dictatorial, y por otra parte, con los análisis de la derrota y las distintas perspectivas de lo que debía ser el PS y su acción política para derrocar a Pinochet.

\title{
Conmemorando en la década de los ochenta
}

Durante los inicios de la década de los ochenta, el PCCH hizo un cambio en su línea política, pasando de la línea de Frente Antifascista, a la línea conocida como Política de Rebelión Popular de Masas (PRPM), lo que significó la apertura a nuevas formas de oponerse a la dictadura. Luis Corvalan Lepe dirá en sus memorias que:

\footnotetext{
${ }^{7}$ Abogado, sobrino de Oscar Schnake, fundador del PS. Mientras realizaba sus estudios fue parte del Comité Central de las JJSS, y en 1969 fue electo diputado. En 1973 fue electo senador. Se le considera uno de los protagonistas del proceso de renovación socialista.
} 
Renato Dinamarca, La elite de la "vieja izquierda" en las batallas de la memoria: la conmemoración del 11 de septiembre en dictadura / The elite of the "old left" in the battles of memory: the commemoration of September 11 in dictatorship, Revista Izquierdas.cl, número 22, enero 2015, ISSN 0718-5049, Santiago de Chile, pp.180-203

Habían pasado siete años desde el golpe militar, la dictadura había logrado destruir la democracia chilena, se afianzaba y buscaba institucionalizarse mediante el plebiscito que había convocado para el día 11 a fin de refrendar su Constitución y asegurar la incesante autoreproducción del sistema. Este plebiscito se realizaría-se realizó- sin registros electorales ni mesas receptoras de sufragios sometidas al control popular...estaba claro que para terminar con la dictadura ya no bastaban las declaraciones de protesta y otros recursos tradicionales. Era necesario agregar a tales métodos, otras formas de lucha, más contundentes. Recurriendo incluso a determinadas acciones de violencia. (1997).

Si bien muchos militantes ya habían experimentado un cambio de actitud frente a la dictadura a fines de la década de los setenta, lo cual se condecía con nuevas políticas de memoria y la creación de nuevas expectativas a futuro, en la década de los ochenta estos esfuerzos por llevar a cabo una oposición fuerte a la dictadura empalmaron con una crisis económica, que estalló en 1982, y que hizo que el descontento y la rabia contra la dictadura se masificaran como nunca había ocurrido en todo el periodo. Desde 1983 a 1986 la memoria como ruptura se difundió ampliamente junto con las expresiones de protesta de la sociedad y de los partidos políticos, dentro de las cuales las del PCCH fueron una de las más radicales. Manuel Fernando Contreras ${ }^{8}$ nos relató al respecto que:

Casi todos los 11 de septiembre hay apagones de luz, en todos se tenía particular consideración en tirar unas cuantas torres abajo, y ¿sabes por qué? por que la oscuridad permitía que la gente saliera a la calle. Era un encapuchado, un gran encapuchado viejo, de cientos de miles de personas que no salían a dejar la cagá', salían a botar una dictadura y no romper quioscos, ni romper semáforos. En ese momento, todos requeríamos ponernos una capucha, porque estábamos ante una dictadura, no estábamos ante una democracia como ahora. Era la gran capucha legítima, en ese momento, eso era el apagón de luz, las dos cosas, demostrar que la dictadura era falible, desde el punto de vista psicológico. Fíjate que yo me acuerdo que tantas veces teorizamos, muchas veces bromeando en La Habana, el fuego, la idea del fuego, porque los sandinistas usaban mucho la cosa de la fogata, como una cuestión simbólica, nosotros siempre tenemos esa idea del fuego, el fuego te convoca, la llama, tu descansas. Hay un hecho mágico en el fuego. Te atrae, te encandila totalmente, el fuego viejo, el fuego es importante, el fuego, que se hagan fogatas, pero apaguemos la luz, lo que sentís con la

\footnotetext{
${ }^{8}$ Manuel Fernando Contreras formó parte de un equipo asesor del Presidente Salvador Allende durante el gobierno de la Unidad Popular. Producido el golpe salió al exilio estando en Cuba y en la República Democrática Alemana. En este último país, formó parte del Grupo de Berlín, quienes estaban encargados de generar información sobre lo que ocurría en Chile, mediante el análisis político de la prensa chilena. Pronto este grupo se transformó en un centro de elaboración crítica de la línea política del partido, y algunos de sus integrantes, entre ellos Contreras, serán quienes elaborarán los fundamentos de la PRPM. Durante los primeros años de la década de los ochenta, Contreras fue el encargado del denominado "Frente Cero", antecedente directo de lo que más tarde sería el Frente Patriótico Manuel Rodríguez.
} 
Renato Dinamarca, La elite de la "vieja izquierda" en las batallas de la memoria: la conmemoración del 11 de septiembre en dictadura / The elite of the "old left" in the battles of memory: the commemoration of September 11 in dictatorship, Revista Izquierdas.cl, número 22, enero 2015, ISSN 0718-5049, Santiago de Chile, pp.180-203

luz apagada, te da la sensación de que es un acto que cubre al país entero, un acto que no deja de ser clandestino, hecho por hombres clandestinos, pero es el acto más publico que podíamos hacer, apagar la luz, cuando todo el mundo pide apagar la luz, cuando apagas la luz, todo el mundo feliz de que apagáramos la luz. No es esta tontería de apagar la luz para el año nuevo, esa es una estupidez, depende del contexto. Aunque la luz la hayan apagado 6 o 11 hombres o mujeres, tiene un profundo sentido de masas, porque sintoniza con el sentimiento mayoritario, la gayá salía a la calle feliz de que le hayan "tocado el poto" a la dictadura viejo, "iputa que valientes estos weones!”(Risas), “iLos cagamos!”, “¡les apagamos la luz, tales por cuales!" Puta y la gayá feliz, y la gayá salía a la calle a tocar la cacerola. Todos podían ser los sandinistas y revolucionarios por veinte minutos, podías tocar la cacerola cuando se apagaba la luz. (2013) ${ }^{9}$.

En este sentido, a la elite del PCCH le había correspondido, mediante distintas instancias, entre ellas las conmemoraciones del 11 de septiembre, construir un imaginario que diera sentido a la vida de los militantes, quienes estaban imbuidos por completo en una lucha por la independencia y la libertad de Chile. La remembranza a lo épico de la independencia de la patria, a la rebeldía del pueblo mapuche y del heroísmo de Allende, tenían la función de dar sentido a la vida de hombres y mujeres que se entregaban por completo y ponían en riesgo sus vidas por derrocar al régimen que consideraban como el más terrorista y nefasto de la historia chilena. Estos militantes actuaron codo a codo con los sectores populares, los trabajadores y las mujeres para impulsar la lucha en contra de la dictadura. Patricio Hales ${ }^{10}$, vocero público del PCCH en la década de los ochenta, nos relató su accionar en el contexto de las protestas populares, en las cuales su función, asignada por el partido, era activar la rebeldía popular:

Había lugares donde no había actos algunos, había lugares donde había pequeños actos y yo hablaba, había lugares donde había reuniones de personas apenas y había otros lugares donde no había nadie, y yo salía a la calle como un predicador y hablaba solo, solo. El partido me celebraba mucho eso, porque yo hablaba solo y la gente se asomaba a las puertas, nada más. Yo sentía que lo que hacía era una contribución a la historia de mi país, y me sentía orgullosísimo de gritar solo y hacer un discurso

\footnotetext{
${ }^{9}$ Cabe mencionar que en la memoria rodriguista la voladura de torres de alumbrado público es un nudo importante de memoria, ya que para muchos fue un hito relevante en un proceso de radicalización política durante la década de los ochenta. Ver (Saldias, Claudio; 1997; Palma, Ricardo; 2001; Carrera, José, 2013).

${ }^{10}$ Patricio Hales actualmente es diputado del Partido Por la Democracia (PPD). En el periodo del gobierno de la Unidad Popular fue dirigente tanto de la FECH, como de Juventudes Comunistas. Durante la década de los ochenta, cuando el PCCH asume la Política de Rebelión Popular de Masas se desempeñó como vocero público del partido. Su posición política se ubicaba dentro de la derecha del partido, es decir, no apoyaba la implementación de la vía insurreccional para dar salida a la dictadura y abogaba por la vocación de masas pacífica del PCCH. Dejó su militancia en el PCCH cuando asume como Presidente de la República Patricio Aylwin, producto de su desacuerdo con las decisiones de la dirección respecto de los contextos que vivía Chile.
} 
aparentemente a la nada y tener la certeza de que había puertas entre abiertas. Yo hice eso en San Pablo a la altura del 8000, en la zona norte, lo hice el $85^{\prime}$ también, el 85', ese 11 de septiembre salí a la zona de San Ignacio, Viel del borde oriente del Parque O' Higgins y hablaba entre medio de los edificios en Avenida Matta, a las seis de la mañana, y gritaba “ipueblo despierta!”(2013).

En muchos casos, estos hombres y mujeres no eran conscientes de la contra conmemoración que llevaban a cabo, sobre todo en un periodo en que las protestas se sucedían diariamente, conformando una suerte de calendario alternativo al tiempo oficial, cuyo objetivo era derrocar a la dictadura. En este sentido, las conmemoraciones del 11 de septiembre dan cuenta que la experiencia comunista había dejado de anclarse en un pasado remoto, para pasar a preocuparse cada vez más del presente, es decir, la respuesta a la represión, así como de la situación económica, y de las expectativas del futuro, es decir, una democracia avanzada. En septiembre de 1983, José Cademartori ${ }^{11}$ dirá en homenaje a Salvador Allende:

Al cumplirse diez años de su muerte, el pueblo de Chile se prepara para dar las batallas finales por su libertad. Después de estos años de resistir la dictadura más oprobiosa de nuestra historia, de incesante batallar por sus derechos, conculcados, la nación chilena se alza como un solo hombre, para decir: BASTA, DEMOCRACIA AHORA (1983: p.39).

De esta manera, fue la labor de los más altos dirigentes del partido la que dio sentido y simbolismo a este accionar, a pesar de que el protagonismo en las protestas fue, en muchos casos, de líderes populares y de los sectores subalternos golpeados por la pobreza. Este periodo llegó a su fin cuando, tras el fallido atentado a Augusto Pinochet, en septiembre de 1986, se produce un irreversible reflujo de la movilización, al tiempo que salen a la luz los conflictos políticos motivados, entre otras cosas, por el monolitismo de la elite del PCCH. En este sentido, el mismo atentado es la expresión de una disputa interna, debido a que dicha acción, llevada a cabo por el Frente Patriótico Manuel Rodríguez, el brazo armado del PCCH, fue realizada sin autorización del partido. Dicha acción buscaba su legitimidad, más que en la autorización del partido, en la falta de justicia por las violaciones a los derechos humanos cometidos por la dictadura de Pinochet, y por esto, era reivindicada como un acto de justicia popular. Por otra parte, algunos de los miembros del comando que la llevó a efecto, eran hijos de emblemáticos militantes comunistas asesinados o hechos desaparecer, lo que implícitamente hace que la acción sea entendida como una justa vuelta de mano del pueblo, en respuesta a las violaciones a los derechos

\footnotetext{
${ }^{11}$ José Cademartori fue miembro del Comité Central del PCCH desde 1961. Durante el gobierno de la UP fue Ministro de Economía, Fomento y Reconstrucción. Luego de estar detenido por tres años tras el golpe, se exilió en Venezuela en donde perteneció al "Grupo Caracas" junto con militantes demócrata cristianos, radicales y socialistas.
} 
humanos. En este sentido, Víctor Díaz Caro, participante en la emboscada e hijo del Secretario General del PCCH desaparecido en 1976, declaró que el objetivo de la acción "no era la venganza", sino que "el objetivo era político y de justicia con nuestro pueblo, para terminar con el dictador" (El Siglo N7657; 1987: p. 3). Por su parte, los dirigentes más conservadores del $\mathrm{PCCH}$ ya habían comenzado a pensar en la forma de desactivar el desarrollo de la línea insurrecta generada en aparato militar.

Creemos que tras el fracaso de la PRPM y la propuesta del PCCH para dar fin a la dictadura, los comunistas disminuyeron su capacidad de interpretar la subjetividad de la mayoría de los chilenos, por lo que también disminuyó su capacidad de encarnar un portavoz de memoria influyente. En este sentido, debido a la errática conducción en el periodo 1987-1988, la memoria "como prueba de una consecuencia ética y democrática" se hizo hegemónica en la izquierda y en parte importante del PCCH, sus sectores que hemos denominado de derecha ${ }^{12}$. Se inició así un periodo de fuertes disputas por el poder al interior del partido, la cual terminó con una salida masiva de dirigentes y militantes de base entre el periodo 1988-1990, configurando así, una de las crisis más profundas que habría vivido el partido (Álvarez, Rolando; 2011).

Por su parte el PS, inició la década de los ochenta viviendo una profunda crisis partidaria, la que se produce luego de la división de 1979, que dio origen a un sin fin de orgánicas que reclamaban para sí la verdadera representación del partido de Allende. Los dos grupos más importantes, se aliaron políticamente con el $\mathrm{PCCH}$ uno, en el Movimiento democrático Popular (MDP), y con la Democracia Cristiana (DC) el otro, en la Alianza Democrática (AD). En este sentido, ambos sectores giraron en torno a otros partidos políticos en los que delegaron la iniciativa política. Los primeros, denominados Partido Socialista Almeyda (PSA), quienes fueron encabezados por Clodomiro Almeyda ${ }^{13}$, fueron los continuadores de la obra iniciada por la "Generación Elena". La otra fracción, el Partido Socialista Renovado (PSR), fue encabezada por Carlos Altamirano ${ }^{14}$, quien impulsó un proceso de crítica y renovación teórica y práctica del socialismo chileno producto de su experiencia tanto en el periodo del gobierno de la UP, como en el tiempo de residencia en los países socialistas de Europa durante el exilio.

A comienzos de los ochenta, todas las fracciones del PS reivindicaban ser los verdaderos herederos de Allende y llevaron a cabo un proceso de legitimación que utilizaba su figura para justificar sus propios proyectos políticos, ya que su heroica muerte había marcado a toda una generación y persistía en la memoria popular. Por una parte, el PSA se asumía como los continuadores de la lucha iniciada el 11 de septiembre por Allende, destacando en las conmemoraciones del golpe militar, desde 1977 hasta el año 1982, su caída en combate en La Moneda. En 1980, un dirigente el PSA en el exilio planteaba que:

\footnotetext{
${ }^{12}$ Entre ellos podemos mencionar a los miembros de la vieja guardia, así como a dirigentes como Patricio Hales o Luis Guastavino.

${ }^{13}$ Clodomiro Almeyda fue un importante dirigente del PS que se radicó en la RDA luego del golpe militar.

${ }^{14}$ Carlos Altamirano era Secretario General del PS en el momento que se produjo el golpe militar de 1973. Luego en el exilio encabezó el proceso de renovación socialista. Algunos dirigentes del sector renovado fueron Ricardo Lagos, Ricardo Núñez, Luis Alvarado, Jorge Arrate, Hernán Vodanovic, Aniceto Rodríguez y Akin Soto.
} 
Salvador Allende lo primero que subrayó fue la necesidad de que el pueblo resistiera y se reorganizara. Su propio combate con las armas en la mano es la máxima expresión de su rechazo enérgico y resuelto a toda actitud claudicante o liquidacionista. Al mismo tiempo, Salvador Allende reafirmó su estatura de dirigente revolucionario al plantear al pueblo, con absoluta nitidez, la disparidad de las fuerzas que en ese momento endentaban. Su lucidez una vez más lo distinguió en su calidad de dirigente. Ajeno a toda demagogia y enemigo del verbalismo inútil e irresponsable, fue firme y certero al señalar que el pueblo no debía dejarse avasallar y llamó a no a caer en una política voluntarista que solo trajera pérdidas inútiles (Santibáñez, Juan; 1980) ${ }^{15}$.

Por otra parte, se asumía la ingenuidad del PS por la excesiva confianza en las instituciones democráticas, lo que influyó en la inadecuada preparación de la ofensiva revolucionaria. De esta manera, se acercaban a definiciones de políticas insurreccionales, aunque su compromiso con la política armada nunca fue tan profundo como lo fue en el PCCH. Siguiendo esta línea, en las conmemoraciones del 11 de septiembre sus críticas apuntaban a deslegitimar al sector socialista que se acercó al centro político, la DC, y que parecía legitimar, a la luz de su propuesta de transición, la Constitución y herencia de la dictadura de Pinochet. Durante la crisis que provocó las protestas iniciadas en 1982, cuestionan la estrategia aperturista proclamadas por los civiles integrados al gobierno por los militares:

El canto de sirena es claro: va dirigido a la DC, a sectores socialdemócratas y de paso a impedir cualquier proceso unitario dentro de la oposición sobre todo cuando la crisis amenaza con profundizarse. Se trata en síntesis de impedir la profundización de las contradicciones al interior del régimen y la crisis económica con medidas de parche y por otro, de sumar fuerzas a su estrategia (Unidad y Lucha $\mathrm{N}^{\circ} 61 ; 1982$ ).

En contraste, el PSA proponía que la única forma de mantenerse leal con Allende era la construcción de un proyecto político alternativo, de carácter democrático, socialista, anticapitalista y anti imperialista. Este proyecto político era similar al que los sectores rupturistas del PS tenían la intención de realizar en el periodo anterior al golpe de estado, el que se desarrollaba a partir de su adhesión al marxismo leninismo y luego del golpe militar, a su cercanía con los socialismos reales, provocada por la solidaridad de estos países con a los exiliados. En este sentido, la figura de Allende también era utilizada para justificar la necesidad de constituir nuevamente la UP y fortalecer la alianza PCCH-PS, que contrastaba con la alianza PS-DC a la que se orientaban los sectores renovados. En el periodo que va desde 1983 a 1988, el PSA volcó su actividad política a la movilización, por lo que en general, dejó de lado el simbolismo en su prensa, haciendo de la figura heroica de Allende

\footnotetext{
${ }^{15}$ Desconocemos la trayectoria de Juan Santibáñez.
} 
Renato Dinamarca, La elite de la "vieja izquierda" en las batallas de la memoria: la conmemoración del 11 de septiembre en dictadura / The elite of the "old left" in the battles of memory: the commemoration of September 11 in dictatorship, Revista Izquierdas.cl, número 22, enero 2015, ISSN 0718-5049, Santiago de Chile, pp.180-203

un emblema al calor de barricada, en la protesta popular. De esta forma, las conmemoraciones del PSA se enmarcaban en la memoria como ruptura lacerante. Patricio Quiroga relató lo siguiente a cerca del recuerdo de Allende:

Es un elemento central para un 4 de septiembre o los 11 de septiembre, era un elemento central para las discusiones políticas, mantener el recuerdo de Allende, en el combate, las alocuciones vez que se hacia una fogata o se volaba un poste de alumbrado, ¿no? eran en torno a Allende, Allende no había muerto, Allende ya era parte de una leyenda... (2013).

Por su parte, el PSR no conmemoró de la misma manera el 11 de septiembre. Caracterizados por ser días de movilización y protesta en el periodo 1983-1986, los 11 de septiembre no eran días en que los miembros del PSR, y de las tendencias renovadas en general, se desplegaran en las calles. Una de las características del sector "renovado", era una nueva concepción de la política, la cual cuestionaba el modelo tradicional de partido de masas y la militancia de "brocha y pintura". En este sentido, pensaban en la actividad política profesionalmente. Así, su preocupación militante estuvo puesta en la creación de agrupaciones que buscaban la unidad socialista, lo cual si bien por una parte, les restaba participación pública en las conmemoraciones y en las protestas en general, en la coyuntura política plebiscitaria fue un capital que les dejó una ventaja considerable frente a otras fracciones y partidos de la izquierda. De esta manera, la actividad conmemorativa del 11 de septiembre era más fuerte en los partidos militarizados. Mientras la dictadura fomentó las conmemoraciones para exaltar el nacionalismo y enaltecer su obra "salvacionista", los partidos de izquierda leninista las asociaron al homenaje de los caídos y a la exaltación de sentimientos como el dolor y la rabia para alimentar la protesta social. Por su parte, los sectores renovados, asumían lo que ellos denominaban una política secular, por lo que dejaban de lado la épica característica de la lucha antidictatorial, la cual estaba cargada de relatos de heroicidad y de gesta patriótica-revolucionaria, para hacer de las conmemoraciones espacios de propuestas para el futuro democrático de Chile. En este sentido, el PSR introducía la idea de "crisis nacional", la que siendo una consecuencia directa de la dictadura, sólo se podía resolver mediante una transición a la democracia y un proyecto de reformas sociales impulsado por los sectores progresistas de la sociedad.

Por otra parte, el PSR destacaba por su reivindicación del socialismo histórico de Chile, el cual se caracterizaba, entre otras cosas, por su crítica de los socialismos reales. Así, este partido reivindicaba a un Allende demócrata, que en la historia de un Chile republicano, había tratado de conjugar la lucha por el socialismo con el régimen democrático liberal, régimen que era considerado una conquista de los trabajadores y no sólo como una dictadura de la burguesía. Cabe mencionar que gran parte de la lucha política de los sectores renovados, sobre todo en el ámbito intelectual, estaba dirigida al cuestionamiento del marxismo leninismo, la vía armada y de sus posibilidades de triunfo en Chile. Es por esto que cuestionaron fuertemente el carácter militar que comenzó a adquirir la protesta durante el periodo 1983-1986, frente a la que proponían el método de la desobediencia civil combinada con la concreción de acuerdos políticos con las Fuerzas Armadas que 
Renato Dinamarca, La elite de la "vieja izquierda" en las batallas de la memoria: la conmemoración del 11 de septiembre en dictadura / The elite of the "old left" in the battles of memory: the commemoration of September 11 in dictatorship, Revista Izquierdas.cl, número 22, enero 2015, ISSN 0718-5049, Santiago de Chile, pp.180-203

aseguraran la transición a la democracia. En este sentido, en sus memorias, Ricardo Núñez ${ }^{16}$ relata su impresión de lo que sucedió en los funerales del religioso André Jarlan, muerto en población La Victoria el día 4 de septiembre de 1984:

Sus funerales se transformaron en un acto de protesta impresionante al que asistimos todos los dirigentes opositores. Al llegar a la población, nos dimos cuenta de que esta se encontraba muy militarizada por diversos grupos como el MIR, el Frente Patriótico Manuel Rodríguez, las Juventudes Comunistas e incluso la Juventud Socialista. Eso nos preocupó. Sin embargo, creo que estábamos en lo correcto al querer evitar que estas protestas, que aparecían como muy sustantivas en ese momento de la lucha, derivaran en enfrentamientos armados como los estábamos comenzando a ver en Santiago. (Fernández, Joaquín et al; 2013: p. 228).

Para los socialistas renovados, las batallas por la memoria fueron importantes, pero no tanto en las conmemoraciones del día 11 de septiembre, sino que por una parte, fueron parte de las discusiones teóricas que llevaron a cabo en centros de estudio como la FLACSO, así como en la lucha social, en la cual la memoria servía para el rescate de procesos de organización popular pasados en función de mostrar una alternativa a la realidad impuesta por la dictadura. En este sentido, creemos que por pragmatismo político, el PSR le asignó una importancia secundaria al acto de conmemoración del 11 de septiembre en el periodo, ya que además de ser una fecha en que el régimen exaltaba mucho su propia obra, también era una fecha en que la izquierda insurrecta llevaba a cabo protestas que escapaban del control de los sectores renovados. Ricardo Brodsky ${ }^{17}$, quien fuera dirigente de la Convergencia Socialista Estudiantil ${ }^{18}$ en esos años, nos relató lo siguiente:

\footnotetext{
${ }^{16}$ Ricardo Núñez es un importante dirigente socialista, miembro del Comité Central durante el Gobierno de la Unidad Popular, exiliado en Europa y luego uno de los principales líderes políticos del sector renovado del PS. Luego de llegada la democracia en reiteradas veces se desempeño como Secretario General del PS.

${ }^{17}$ Ricardo Brodsky fue militante del MAPU durante todo el periodo dictatorial. Miembro de la Resistencia en la década de los setenta y ochenta, participó activamente en la reconstrucción de la FECH, de la cual fue el primer Secretario General. En este contexto, también fue un importante dirigente de la Convergencia Socialista. A mediados de los ochenta, rompe con el MAPU, y más tarde, fue uno de los fundadores del Partido Por la Democracia, del cual llegó a ser Secretario General. En la actualidad es el Director Ejecutivo del Museo de la Memoria y los Derechos Humanos.

${ }^{18}$ La Convergencia Socialista fue una forma orgánica que tomó el proceso de renovación del socialismo chileno en el exilio. En este sentido, tiene su origen en las reuniones de Ariccia, en las cuales se trato el tema del socialismo chileno y sus perspectivas. La primera se llevó a cabo en marzo de 1979 y la segunda en enero de 1980, estando esta última destinada a encontrar formas de trabajo común que contribuyeran "a la mayor unidad y desarrollo de la vertiente socialista". (Ampuero, Raúl; 2002: pp. 21-22).

Cabe acotar que la Convergencia Socialista tuvo dos vertientes, una intelectual, en donde destacaron intelectuales del MAPU tales como Manuel Antonio Garretón, José Joaquín Brunner o Eugenio Tironi, y una política, en donde destacó el rol de Ricardo Brodsky como dirigente estudiantil y de la cual también era parte el PSR. Ver, (Fernández, Joaquín et al, 2013).
} 
Después con las protestas, del 83' en adelante, el 11 de septiembre toma otro tono y se produjeron movilizaciones mucho más grandes, protestas nocturnas, eso fue así. Ahora, yo por lo menos en el recuerdo mío es que lo más importante no era tanto el 11 de septiembre, era más el $1^{\circ}$ de mayo, habían como otras fechas que nos parecían más movilizadoras digamos, septiembre era muy tomado por el gobierno (2014).

En este sentido, los portavoces socialistas de la memoria como compromiso democrático utilizaron otros nudos de memoria para resaltar tanto la figura de Allende y su proyecto, por ejemplo, las fechas de su natalicio o del aniversario de la fundación del PS, así como la trayectoria del movimiento social chileno y sus principales referentes organizativos. Brodsky lo plantea así:

Había obviamente por parte de la Junta un esfuerzo por negar todo lo que era la memoria del Chile republicano, del Chile democrático y sobre todo, obviamente, de las fuerzas de izquierda y de los movimientos sociales, como la Central Única de Trabajadores, la Federación de Estudiantes, las agrupaciones campesinas, los movimientos poblacionales, etc., todo eso fue borrado, fue suprimido de la memoria colectiva de los chilenos. Entonces yo siempre he dicho que la lucha contra la dictadura, sobre todo en el mundo social, tuvo mucho que ver con la recuperación de la memoria del Chile republicano, democrático, social. Y eso fue el gran esfuerzo que se hizo desde el movimiento estudiantil, en todo el proceso que significó recuperar la $\mathrm{FECH}$, el proceso de recuperar la Central Unitaria de Trabajadores. Entonces esa lucha, que es una lucha en cierta forma también de la memoria, creo que fue lo más relevante (2014).

Por otra parte, la idea de acuerdo político con los militares, defendida por el socialismo renovado en virtud de su acuerdo con la DC, cuyo propósito era la reconstrucción nacional dando prioridad al ámbito económico, tenía inevitablemente como contracara una cuota importante de olvido de las violaciones a los derechos humanos y también de impunidad de los culpables de estas, lo cual era una visión que se contraponía frente a la izquierda leninista que planteaba que la necesidad de la justicia y la verdad como un principio incuestionable. Sin duda que este elemento hará problemática la relación de la democracia y la memoria del pasado reciente en Chile. Al respecto, citamos al dirigente socialista Ricardo $\operatorname{Lagos}^{19}$ refiriéndose a la transición a la democracia:

\footnotetext{
${ }^{19}$ Ricardo Lagos fue parte de un pequeño grupo socialista llamado "Los Suizos", el que se caracterizó por mantenerse al margen de las disputas internas en la década de los setenta. Además fue importante referente político y portavoz de la memoria como compromiso democrático en la transición. Por último, fue fundador de PPD y en 1998 electo Presidente de la República representando a la Concertación de Partidos por la Democracia.
} 
El socialismo debe visualizar una política de transición a la democracia no sólo como un mecanismo para reivindicar una institucionalidad perdida, sino también para exigir un pacto social que permita que los sectores populares vean en esa incipiente democracia una voluntad nacional de remediar las injusticias de las cuales ellos han sido las principales víctimas. No es sólo remediar las injusticias producto de las violaciones a los derechos humanos en que ha incurrido la dictadura; también hay que remediar las injusticias para con los sectores populares, que han sido afectados por las políticas económicas (1987).

Luego del fracaso del atentado a Pinochet, las posibilidades de continuar con la lucha armada se redujeron, al mismo tiempo que la dictadura tomaba la ofensiva política. Como consecuencia, se produce un giro político en el PSA, el que termina aceptando la estrategia política del PSR, el acuerdo con las fuerzas armadas, llamando a la inscripción electoral y la participación en el plebiscito de 1988 que decidiría la permanencia de Pinochet en la Presidencia de la República.

En el contexto plebiscitario, las conmemoraciones del 11 de septiembre sirvieron de propaganda electoral, y el plebiscito fue significado como una batalla en la cual la oposición podía vencer a Pinochet. Esta forma en que se desencadenó la transición ayudó a que la memoria como compromiso democrático se convirtiera en la memoria dominante durante el próximo periodo democrático.

\section{Conclusión}

Nuestra perspectiva ha destacado la forma en que las conmemoraciones del $11 \mathrm{de}$ septiembre de la elite de la izquierda sirvieron como elemento de lucha política, tanto en un periodo de reconstrucción, en la década de los setenta, como en un periodo en donde la actividad política vuelve al espacio púbico, la década de los ochenta. Este es un elemento que además da cuenta de la importancia que ha adquirido la memoria en la política y en la sociedad, por lo que la convierte en un objeto de investigación de gran relevancia.

Las disputas por la memoria del 11 de septiembre no acabaron en este periodo sino que se mantienen hasta nuestros días. La forma en que se sucedieron los hechos, y la forma de desarrolló de la transición, que significó olvido, impunidad y privatización de la justicia bajo el lema de la Reconciliación Nacional en la década de los noventa, significó también la polarización entre quienes reclamaban verdad y justicia y quienes reivindicaban el papel de los militares en la crisis del periodo 1970-1973. Por otra parte, aquellos que aceptaron las reglas de la nueva democracia, durante casi una década prefirieron respetar un pacto de silencio a favor del consenso y la paz social, lo que podría ser homologado con una falsa costra que buscaba tapar las heridas por el pasado violento. La falta de justicia en Chile, ha generado la sensación de impunidad, y ha contribuido a que parte de las manifestaciones de memoria en democracia se tornen en las manifestaciones conflictivas y también de 
violencia política. En este sentido, la presente investigación nos ha dado luces sobre cómo se gestó en la izquierda la lucha por la memoria del 11 de septiembre.

Podemos agregar que existe un importante vacío en la historiografía sobre lo que se ha denominado "tradición del septiembre negro" (Candina, Azun; 2002), denominación que se refiere a las actividades de protestas desarrolladas en el mes de septiembre y que resulta ser un fenómeno que liga la violencia política con la memoria y que aún está presente en la sociedad. En esta perspectiva queda pendiente la investigación de las memorias de partidos como el Movimiento de Izquierda Revolucionaria, el Frente Patriótico Manuel Rodríguez y el MAPU-Lautaro, quienes son parte de lo que se ha denominado como insurgencia en el Chile reciente y que fueron portavoces de importantes críticas en el temprano Chile democrático (Goicovic, Igor: 2010). Durante los últimos años, específicamente desde el 2003, el fenómeno de la violencia ha tenido especial atención de cientistas políticos y los medios de comunicación, en cuanto estos se preguntan sobre la participación del lumpen en dichas protestas (Joignant, Alfredo; 2007). ¿Cuánto de memoria tienen estas manifestaciones? ¿Cuánto de vandalismo? ¿Cuánto de disputa política? Es una interrogante a responder a futuro.

Por otra parte, también resulta pertinente mencionar que queda pendiente una investigación sobre las conmemoraciones y la memoria de las elites políticas, los movimientos sociales, con énfasis en el movimiento de derechos humanos, y los medios de comunicación en el periodo que se inicia con el plebiscito de 1988 a la actualidad, lo cual puede arrojar muchas luces de cómo las generaciones actuales nos relacionamos con el pasado traumático. Por último, la pregunta sobre los usos políticos del pasado en el presente, nos puede conducir a evaluar en qué medida los marcos de memoria propuestos por Stern siguen vigentes y qué otros marcos de memoria, así como portavoces, han nacido en el Chile de hoy.

Recibido: 21 septiembre 2014

Aceptado 28 noviembre 2014

\section{Bibliografía}

Álvarez, Rolando. Desde las sombras, una historia de la clandestinidad comunista (19731980). Santiago: LOM, 2003.

- Arriba los pobres del mundo, cultura e identidad política del Partido Comunista de Chile entre democracia y dictadura, 1965-1990. Santiago: Ed. LOM, 2011.

Ampuero, Raúl. Ampuero: El socialismo Chileno. Santiago: Tierra Mía, 2002.

Bravo, Viviana. ¡Con la razón y la fuerza venceremos! La rebelión popular y la subjetividad comunista en los 80’. Santiago: Ariadna, 2010. 

septiembre en dictadura / The elite of the "old left" in the battles of memory: the commemoration of September 11 in dictatorship, Revista Izquierdas.cl, número 22, enero 2015, ISSN 0718-5049, Santiago de Chile, pp.180-203

Candina, Azun. "El día interminable. Memoria e instalación del 11 de septiembre de 1973 en Chile (1974-1999). Jelin, Elizabeth (ed.), Las conmemoraciones: Las disputas en las fechas "in-felices". Madrid: Siglo veintiuno, 2002.

Carrera, José. Somos tranquilos pero nunca tanto... Santiago: CEIBO, 2013.

Dinamarca, Renato. Memoria y conmemoración: el 11 de septiembre de la elite comunista en tiempos de dictadura. Tesis para obtener el grado de Licenciado en Historia. Santiago: Universidad Academia de Humanismo Cristiano, 2013. [Citado el 22-09-2014], disponible en: http://bibliotecadigital.academia.cl/bitstream/123456789/1206/1/this\%2081.pdf

Drake, Paul. Socialismo y Populismo, Chile 1936-1973. Valparaíso: Universidad de Valparaíso, 1992.

Fernández, Joaquín et al. Ricardo Núñez. Trayectoria de un socialista de nuestro tiempo. Santiago: Universidad Finis Terrae, 2013.

Gillis, John. "Memoria e Identidad: la historia de una relación" en Gillis, John (ed.), The politics of national identity. Traducción de Natalie Abad de Ruhr, EEUU: Princeton University Press, 1996 [citado el 22-05-2013], disponible en: http://www.cholonautas.edu.pe/memoria/gillis.pdf

Goicovic, Igor, Transición y violencia política en Chile (1988-1994), Revista Ayer Nº 79, Madrid, 2010, pp. 59-86.

Gutiérrez, Eduardo. Ciudades en las sombras. Historia no oficial del Partido Socialista de Chile. Santiago: Editare, 2003.

Herrera, Tatiana. Capacidad de renovación de los liderazgos políticos chilenos. Los procesos de generación, desarrollo y recambio. Santiago: Universidad Central, 2005.

Jelin, Elizabeth (ed.). Las conmemoraciones: Las disputas en las fechas "in felices". Madrid: Siglo veintiuno, 2002.

. Los trabajos de la memoria. Buenos Aires: Siglo Veintiuno, 1998.

Joignant, Alfredo. Un día distinto. Memorias festivas y batallas conmemorativas en torno al 11 de septiembre en Chile, 1974-2006. Santiago: Universitaria, 2007.

Moyano, Cristina. La izquierda chilena y sus elites, sujetos, redes y cultura política en una época de excepción. 1973-1989. Santiago: proyecto Fondecyt post doctoral inédito, 2008.

. "Los líderes de la izquierda. Configuración de las elites en el imaginario político chileno dictatorial y el rol de las revistas políticas de oposición, 1973-1989”. 
Bicentenario vol. 8, n¹. (2009).

Nagle, John. Sistema y sucesión. Las bases sociales del reclutamiento de la élite política. México: Premia, 1979.

Ortiz, Edison. El socialismo chileno. De Allende a Bachelet (1973-2005). Santiago: S/E, 2007[citado el 27-01-2014]) disponible en: http://www.socialismochileno.org/PS/index.php?option=com_content\&task=view\&id=1896\&Itemid=39

Palma, Ricardo. Una Larga cola de acero (Historia del FPMR 1984-1988).Santiago: LOM, 2001.

Rabotnikof, Nora. "Política y tiempo: pensar la conmemoración", Revista Sociohistórica $\mathrm{n}^{\circ}$ 26, 2009[citado el 10-11-2013, p. 189, disponible en:

http//www.fuentesmemoria.fahce.unlp.edu.ar/art_revistas/pr.4513/pr.4513.pdf

Saldias, Claudio. Nacer en Primavera, Vol. 1. Santiago: Ediciones Rodriguistas, 1998.

. Nacer en Primavera, Vol. 2. Santiago: Ediciones Rodriguistas, 2007.

Stern, Steve. "De la memoria suelta a la memoria emblemática: hacia el recordar y el olvidar como proceso histórico en Chile". Garcés, Mario y Milos, Pedro eds. Memorias para un nuevo siglo. Chile, miradas a la segunda mitad del siglo XX. Chile: LOM, 2000.

Luchando por mentes y corazones. Las batallas de la memoria en el Chile de Pinochet. Santiago: Universidad Diego Portales, 2013.

Yocelevzky, Ricardo. Chile: partidos políticos, democracia y dictadura. 1970-1990. Santiago: FCE, 2002

\section{Prensa}

Cademartori, José. "A diez años del putsch fascista: el presidente héroe”, Boletín Exterior №61, septiembre-octubre, 1983.

Juventudes Comunistas. Basta $\mathrm{N}^{\circ} 4$, "O'Higgins: un verdadero patriota revolucionario". Septiembre, 1979[citado el 16-10-2013], disponible en: http://cronopio.flacso.cl/fondo/pub/publicos/BAS N 04.pdf

Lagos, Ricardo. "Entendimiento nacional y los sin voz", en Revista Convergencia $N^{\circ} 11$, abril-junio, 1987[citado el 28-04-2014], disponible en: www.socialismochileno.org/convergencia/convergencia11.pdf

Partido Comunista. "declaración del PCCH: compatriotas: ¡Solo unidos derrotaremos al 
Renato Dinamarca, La elite de la "vieja izquierda" en las batallas de la memoria: la conmemoración del 11 de septiembre en dictadura / The elite of the "old left" in the battles of memory: the commemoration of September 11 in dictatorship, Revista Izquierdas.cl, número 22, enero 2015, ISSN 0718-5049, Santiago de Chile, pp.180-203

fascismo!", en Boletín Exterior N ${ }^{\circ}$ 20, noviembre-diciembre, 1976. [Citado el 16-10-2013]: disponible en: http://es.scribd.com/doc/99202181/Boletin-del-Exterior-Partido-Comunistade-Chile-N\%C2\%BA20

Partido Comunista. Declaración 9 de septiembre, 1986, citada en El Siglo $N^{\circ} 7657$, Septiembre, 1987 [citado el 14-11-2013], disponible en: http://cronopio.flacso.cl/fondo/pub/publicos/SGLO N 7657.pdf

Partido Socialista. "Hace tres años", Informativo N²2 (septiembre, 1976[citado el 06-022014]) pp. 2-3, disponible en: $\underline{\text { http://www.socialismo- }}$ chileno.org/apsjb/1976/Informativo\%2022.PDF

Partido Socialista. "5 años de dictadura, 5 años de lucha” (editorial), Unidad y Lucha N³2, (septiembre, 1978[citado el 10-02-2014]), disponible en: http://www.socialismochileno.org/UyL/UyL N 32.pdf

Partido Socialista Almeyda, Unidad y Lucha, № 61, Octubre, 1982[citado el 20-02-2014], disponible en: http://www.socialismo-chileno.org/UyL/uyl_N_61.pdf

Partido Socialista- Regional Europa. De la dialéctica de la derrota, a la victoria: un nиеvo socialismo para Latino América, (septiembre, 1978[citado el 12-02-2014]), disponible en: http://www.socialismo-chileno.org/apsjb/1978/regional_europa_78.pdf

Santibáñez, Juan. "A diez años de la UP”, en JJSS, Boletín Juventud Socialista de Chile, septiembre, 1980[citado el 21-02-2014], disponible en: http://www.socialismochileno.org/apsjb/1980/b_js_9_80.pdf

\section{Entrevistas}

Manuel Fernando Contreras, 02-09-2013.

Patricio Hales, 08-10-2013.

Patricio Quiroga, 23-09-2013.

Ricardo Brodsky, 20-03-2014. 